\title{
Cap-and-Trade, Emissions Taxes, and Innovation
}

\author{
Suzanne Scotchmer, University of California, Berkeley
}

\section{Executive Summary}

Emissions taxes and carbon caps can both lead to efficient production of energy, in the sense of controlling carbon emissions to the extent that is efficient with existing technologies. However, the regulatory policy has a second objective, which is to create incentives to develop lower-carbon technologies. With both objectives in mind, does one policy dominate the other? The answer depends partly on whether the regulated price of energy is in the elastic or inelastic part of the demand curve. It also depends on the size of the improvement. Under tax regulation, an innovator can always profit from diffusing the clean technology to all producers. This is not true under a carbon cap because diffusion expands energy supply, reducing the price of energy and of allowances and eroding the producers' willingness to pay for licenses. Under cap-and-trade regulation, the regulator has less ability to control the price of energy while ensuring productive efficiency (full diffusion). Because there is little incentive to invest in a larger improvement than will be fully diffused, cap-and-trade regulation limits innovation in a way that is avoided by a tax.

\section{Introduction}

Carbon emissions are an important by-product of producing energy, and it is widely accepted that they contribute to global warming. Managing this problem will require lower-carbon technologies that are not yet available. This raises the question of how regulation can best create incentives to innovate.

Any regulatory mechanism that makes it expensive to emit carbon will encourage the development of lower-carbon technologies. Tradable carbon allowances have that effect, as do emissions taxes. However, these regulatory instruments are not equivalent for innovation, and environmental economists have long been interested in the question of which is superior. 
Two types of innovation have been addressed in the economics literature. One concerns abatement technologies (Milliman and Prince 1989; Parry 1995, 2003; Jung, Krutilla, and Boyd 1996; Fischer, Parry, and Pizer 2003), and the other concerns replacement technologies (Laffont and Tirole 1996; Denicolo 1999; Montero 2010). For example, gasolinepowered automobiles might eventually be replaced by those with affordable hydrogen combustion. Electricity might eventually be produced with solar power rather than coal. These improvements do not require retrofitting or "abating," but instead require that producers switch to the lower-carbon technology. I will discuss replacement technologies since those seem most germane to the problem of global warming.

Regardless of which type of regulation is chosen, an emissions tax or a carbon cap, the policy must perform two tasks. One task is to encourage innovation. The other task is to ensure "static efficiency" given the best technology available.

Static efficiency has two aspects, which we might call "productive" efficiency and "consumption" efficiency. Productive efficiency means that energy is produced at the cheapest social and private cost. It requires that the social and private cost of producing energy is the same at the margin for each producer, possibly accounting for efficient abatement measures. In this paper, productive efficiency means only that energy producers switch to the lower-carbon technology. Consumption efficiency concerns the optimal consumption of energy and emissions, assuming that production is efficient. It requires that the price of energy is equal to the private and social marginal cost of producing it.

Because a carbon-reducing innovation reduces the social cost of emissions, the new technology should optimally lead to an expansion in energy consumption. Moreover, if energy production is in the inelastic portion of the demand curve, total emissions should go down: the benefits should be taken partly as an increase in energy consumption and partly as a reduction in emissions. If energy production is in the elastic part of the demand curve, energy production should expand so much that emissions actually increase, even though energy is produced with a lower emissions rate. This is shown below.

With a fixed regulatory policy, a reduction in the emissions rate will change the amount of energy and emissions that are produced, but not in a way that is optimal. As a consequence, regulators might be tempted to adjust the regulatory policy. Alternatively, the anticipated adjustment could be written into the policy. The innovator's reward depends on the policy that is anticipated, not on the policy in effect beforehand. I discuss three different adjustment scenarios: a fixed policy such as the one that is initially efficient, 
an adjustment that achieves the efficient output of energy and carbon using the cleaner technology, and more stringent policies that are designed with innovation in mind rather than static efficiency. The second adjustment (to ex post efficiency) is always possible under tax regulation, but not always under cap-and-trade regulation, because the proprietor might not make the clean technology available to all energy producers. However, if static efficiency can be achieved ex post under both policies, tax regulation and an equivalent carbon cap are equally lucrative to the proprietor.

The thrust of this paper is that tax regulation is more lucrative for a clean-technology innovator than a carbon cap when demand for energy is inelastic, and vice versa when demand for energy is elastic. The essential difference is that cap-and-trade leads to an expansion in energy production, but tax regulation might not. With tax regulation, there is no contradiction between widespread licensing and charging a royalty that maintains a high price of energy, in particular, the price that prevailed before the innovation. This is not possible under a carbon cap. Licensing without an expansion in energy production leads to an excess supply of allowances. The price of allowances falls, leading to more production of energy, at a lower price. This has two consequences. First, the fall in the price of allowances reduces the producers' willingness to pay for licenses. Second, the proprietor might want to mitigate the fall in prices by licensing only some of the energy producers. As a consequence, cap-and-trade can lead to productive inefficiency.

In Section II, I discuss how the efficient production of energy and emissions depend on the emissions rate. In Section III, I argue that an innovator always has an incentive to diffuse the innovation to all energy producers under tax regulation but might not do so under cap-and-trade regulation.

In Sections IV, V, and VI, mostly following Denicolo (1999), I show that tax regulation is generally more conducive to innovation than cap-andtrade when demand is inelastic, and vice versa when demand is elastic. In Section VII, mostly following Laffont and Tirole (1996), Denicolo (1999), and Montero (2010), I address the special problems that arise when the proprietary technology is very clean, such as having a zero emissions rate. This is where the conflict between static efficiency and the incentive to innovate is particularly acute and where the regulator may want to commit to a policy that does not achieve static efficiency.

\section{Static Efficiency: Balancing Emissions and Energy}

Suppose that producing $e$ kilowatt-hours of energy emits ce units of carbon. That is, $c$ is the carbon emissions rate. Let $\mathrm{E}(\cdot)$ be the demand for 
energy, shown in figure 1. I will refer to its inverse as $\mathrm{P}(\cdot)$ and will refer to gross profit in the energy market as $\mathrm{G}(e) \equiv e \mathrm{P}(e)$.

For simplicity, suppose that the social cost of releasing carbon is the same for every carbon ton, say $h$. In the figures below, I will assume that the marginal cost of producing energy is zero, even though that is unrealistic. This allows us to isolate the effect of regulation on prices without cluttering the diagrams with marginal cost curves.

I will use the term static efficiency to refer to the optimal supply of energy and associated carbon emissions. Static efficiency requires that all the producers use the cleanest technology; otherwise emissions are unnecessarily high given the supply of energy.

The efficient supply of energy depends on the emissions rate. When the emissions rate falls from $c_{0}$ to $c$, the social cost of emissions per kilowatt-hour (equivalently, the optimal price of energy) falls from $c_{0} h$ to $c h$. In figure 1, the optimal supply of energy increases from $\mathrm{E}\left(c_{0} h\right)$ to $\mathrm{E}(c h)$ Total emissions go from $\mathcal{c}_{0} \mathrm{E}\left(\mathcal{c}_{0} h\right)$ to $c \mathrm{E}(c h)$. If the efficient price $c_{0} h$ is in the inelastic part of the demand curve (i.e., if $c_{0} h$ is smaller than the revenue-maximizing price of energy), then the gross profits in the energy market satisfy $c_{0} h \mathrm{E}\left(c_{0} h\right)>\operatorname{ch} \mathrm{E}(c h)$. When we divide by $h$, this implies that total emissions should optimally decrease. More surprisingly, if the efficient price $c h$ is in the elastic part of the demand curve (ch larger than the revenue-maximizing price of energy), then

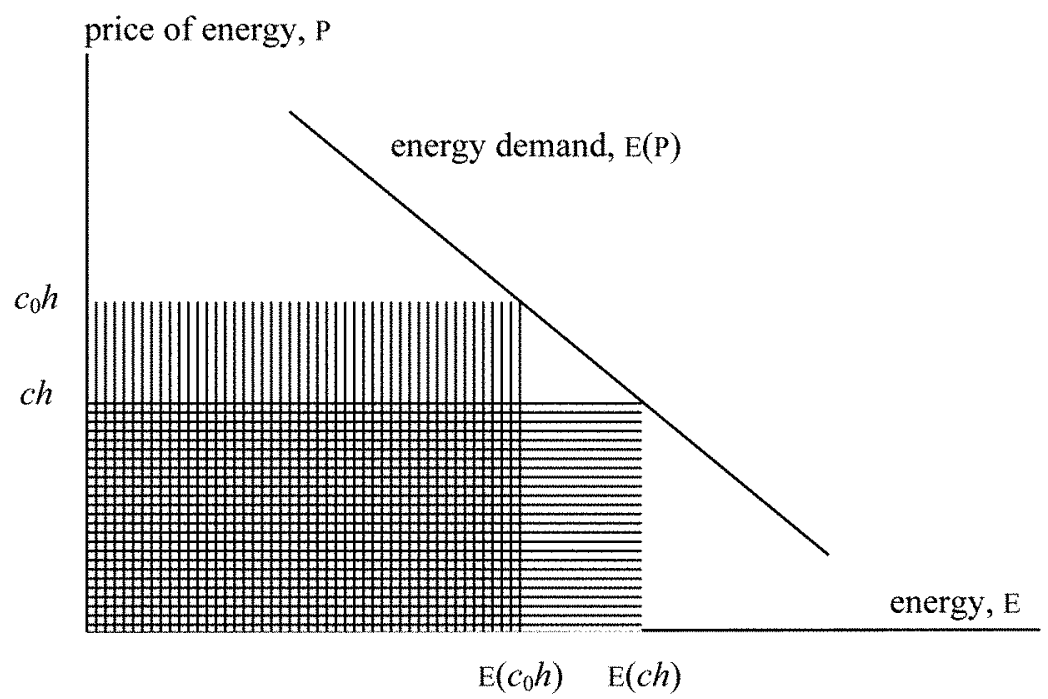

Fig. 1. Optimal energy supply and emissions, as they depend on the emissions rate 
$c_{0} h \mathrm{E}\left(c_{0} h\right)<c h \mathrm{E}(c h)$, which implies that emissions should optimally increase rather than decrease. That is, when the emissions rate goes down, the supply of energy should increase so much that emissions also go up. In that area of the demand curve, the willingness to pay for energy is high relative to the social harm from emissions.

-When a lower emissions technology becomes available, it is optimal to take the benefits of that technology as an increase in energy production and a decrease (respectively, increase) in carbon emissions when the energy production is in the inelastic (respectively, elastic) part of the demand curve.

In what follows, I assume that the initial technology with emissions rate $c_{0}$ is nonproprietary. I then suppose that a proprietor has introduced a new technology with a lower emissions rate, say $c<c_{0}$. I will refer to the percentage reduction in emissions rate, $\left(c_{0}-c\right) / c_{0}$, as the size of the improvement.

I assume that the energy sector is competitive and that the marginal resource cost of producing energy is zero. Thus, in the absence of regulation, the competitive price of energy is zero. Under tax regulation, the competitive price of energy is equal to the taxes paid plus any royalty paid; under a carbon cap, the competitive price of energy is equal to the cost of allowances plus any royalty paid.

\section{The Problem of Diffusion}

In order to compare the incentive effects of the two regulatory policies, we must first ask whether an innovation, once it is achieved, will be diffused fully to the producers of electricity. By full diffusion, I mean that no energy is produced with the old technology. The cleaner technology will be fully diffused under tax regulation, but not necessarily under a cap-and-trade policy. That is, except for lags due to depreciation of old capital (not considered here), tax regulation will lead to productive efficiency whereas a carbon cap might not.

First consider tax regulation. If the market is regulated with a tax, say $\tau$, the tax should be levied on emissions, not on the energy that is produced. This encourages energy producers to avoid emissions and will, it is hoped, encourage innovation to cleaner technologies. The optimal emissions tax is equal to the social cost of emitting each carbon ton, $\tau=h$. In a competitive market in which producers make zero profit and assuming that the technology is nonproprietary so that there is no royalty, the 
equilibrium price of energy is ch, which achieves "consumption efficiency," that is, the efficient balance of energy production and emissions.

Using the proprietary technology will typically require a royalty, say $\gamma$, which I assume is levied on kilowatt-hours of energy produced with the new technology. It must satisfy $\gamma \leq \tau\left(c_{0}-c\right)$, where $\tau$ is the tax on emissions. Otherwise producers prefer the old technology. The price of energy is the minimum of $c_{0} \tau$ and $c \tau+\gamma$, and producers are indifferent between the technologies if these are equal. The proprietor will always find it optimal to license all the producers. If only some of the producers are licensed (and the two technologies are equally profitable), the proprietor can attract the rest of them with a small decrease in the royalty. This will increase profit.

With the maximum royalty, energy production and the price of energy are the same as with the old technology, namely, $c_{0} \tau=\gamma+\mathcal{c} \tau$. The proprietor's share of gross profit in the energy sector is then the fraction of the price he collects as a royalty, $\gamma / c_{0} \tau=\left(c_{0}-c\right) / \mathcal{c}_{0}$, namely, the size of the improvement. However, as we will see below, if demand is elastic, the proprietor might want to charge a smaller royalty, $\gamma<\tau\left(\mathcal{C}_{0}-c\right)$, in order to expand the number of licensees. As compared to charging the maximum royalty, he then collects a smaller fraction of larger gross profit in the energy market.

Under tax regulation, there is no contradiction between full diffusion and maintaining a high price of energy with the royalty. When demand is inelastic, this is not true under a carbon cap. Under a carbon cap, increasing the fraction of the market that is supplied by licensees causes the price of energy and the price of allowances to fall. Under tax regulation, the proprietor can maintain the previous price of energy, $c_{0} \tau$, while collecting a share $\left(c_{0}-c\right) / \mathcal{c}_{0}$ of each licensee's profit and, thus, collecting the share $\left(c_{0}-c\right) / c_{0}$ of gross profit in the energy market. Under a carbon cap, any licensing at all must increase energy supply and cause the price of energy to fall because fewer allowances are used by producers using the clean technology. If the supply of energy did not expand, there would be an excess supply of allowances. In the inelastic part of the demand curve, the fall in price causes gross profit in the energy market to fall.

The conclusions can be seen explicitly by writing down the equilibrium relationships between the royalty rate on energy production, $\gamma$, and the allowance price, say $q$. The price of energy will be $\mathrm{P}(e)$, where $e$ is the total amount of energy that is produced, up to the maximum that is possible with the clean technology, $\mathbb{C} / c$. The prices are related by the equations (1), which say that producers make zero profit using either 
technology. If producers strictly preferred the new technology (i.e., if $\left.c_{0} q>c q+\gamma\right)$, the proprietor could raise the royalty a bit without losing licensees:

$$
\begin{aligned}
& \mathrm{P}(e)=c_{0} q, \\
& \mathrm{P}(e)=c q+\gamma .
\end{aligned}
$$

These zero-profit expressions again assume that producers are competitive, so that the price of energy is the sum of the royalty $\gamma$, if paid, and payments to the owners of allowances, either $c_{0} q$ or $c q$, depending on which technology is used.

Solving the two equations, we get

$$
\gamma=\left(\frac{\mathcal{c}_{0}-\mathcal{c}}{\mathcal{c}_{0}}\right) \mathrm{P}(e)
$$

Regardless of the extent of licensing, the proprietor receives a fraction $\left(c_{0}-c\right) / c_{0}$ of the energy price from the licensees. The rest is paid to the owners of allowances. The expressions (1) show that a higher royalty $\gamma$ leads to a higher allowance price $q$, a higher price of energy, and, implicitly, fewer licensees. If less energy is demanded, a larger share of it must be supplied by high-carbon producers.

In figure 2 , the carbon cap is $\mathbb{C}$, and an improvement $\left(c_{0}-c\right) / c_{0}$ can allow energy supply to expand from $\mathbb{C} / c_{0}$ to $\mathbb{C} / c$. However, full diffusion might not be the most profitable choice when demand is inelastic.

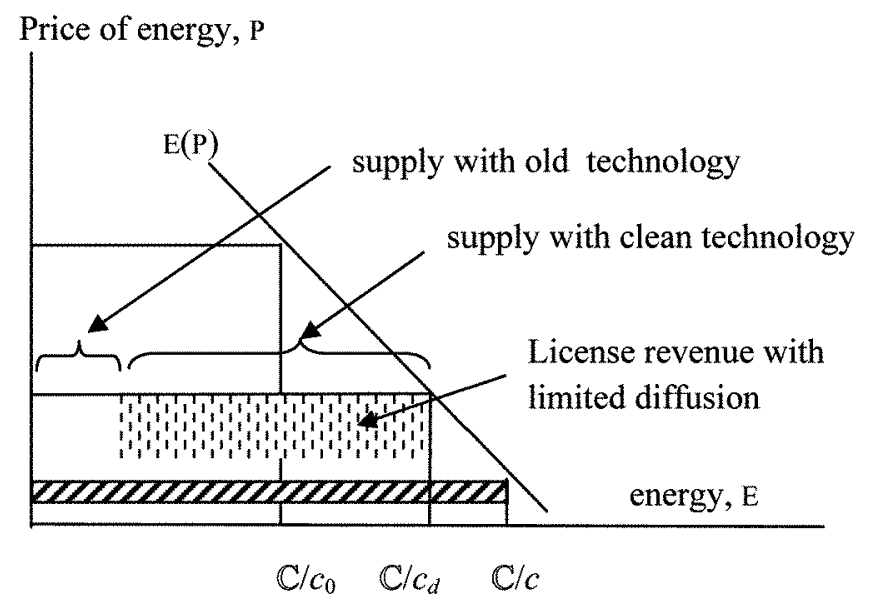

Fig. 2. Limited diffusion of the cleaner technology when the emissions rate falls 
Figure 2 shows a situation in which the optimal royalty rate leads to energy supply $e=\mathbb{C} / c_{d}<\mathbb{C} / \mathcal{c}$, that is, incomplete diffusion. A lower royalty would allow energy production to expand to its maximum, $\mathbb{C} / c$, but that would reduce the proprietor's revenue. The shaded areas show the proprietor's licensing revenue with limited diffusion and with full diffusion. In each situation, the proprietor earns a share $\left(c_{0}-c\right) / c_{0}$ of the licensees' profit. Full diffusion to $\mathbb{C} / \mathcal{c}$ is not optimal because the price of energy falls too much. Even though the proprietor gets a fixed share of the licensees' profit and even though there are more licensees with full diffusion than with partial diffusion, the licensees make less gross profit.

We can conclude from this that there is a maximum expansion in energy supply, in particular, to $\mathbb{C} / \mathcal{c}_{d}$, that the proprietor will facilitate. If the improvement is small, such that $\mathbb{C} / \mathcal{C}<\mathbb{C} / \mathcal{c}_{d}$, the proprietor will diffuse the innovation fully, and the innovator gets a share $\left(c_{0}-c\right) / \mathcal{c}_{0}$ of gross profits in the energy market. If the improvement is large, such that $\mathbb{C} / c_{d}<\mathbb{C} / \mathcal{c}$, the proprietor will limit diffusion. He still earns a share $\left(c_{0}-c\right) / \mathcal{c}_{0}$ of his licensees' gross profits, but that is only part of total gross profits in the energy market.

Of course, as I have already mentioned, the proprietor can limit diffusion without literally withholding his offer from some of the producers. He can achieve the desired outcome by charging a higher royalty. Given a royalty $\gamma$, producers will enter until the competitive supply, say $\mathbb{C} / \mathcal{c}_{d}$, satisfies

$$
\gamma=\left(\frac{c_{0}-\mathcal{c}}{c_{0}}\right) \mathrm{P}\left(\frac{\mathbb{C}}{\mathcal{c}_{d}}\right) .
$$

This royalty is larger than the royalty that would yield full diffusion, namely,

$$
\gamma=\left(\frac{c_{0}-c}{c_{0}}\right) \mathrm{P}\left(\frac{\mathbb{C}}{c}\right) .
$$

The problem of diffusion feeds back into the problem of innovation. Under tax regulation, an innovator's licensing revenue increases with the size of the improvement. This is not true under a carbon cap for improvements larger than $\left(c_{0}-c\right) / c_{0}{ }^{1}$

As discussed by Fischer et al. (2003) for abatement technologies, an intuitive explanation for why the proprietor limits diffusion is that licensing causes the price of allowances to fall. Since the producers' willingness to pay for licenses depends on the avoided payments for allowances, the fall in the allowance price reduces the producers' willingness to pay and cuts into licensing revenue. 
The conclusions of this section are as follows:

- A proprietary clean technology will be fully diffused under tax regulation but not under a carbon cap if the improvement is large.

- Under cap-and-trade regulation, an innovator cannot increase licensing revenue by investing in a larger improvement than would be fully diffused.

- If both the original price of energy and its price under full diffusion are in the elastic part of the demand curve, innovations will be fully diffused.

The last point follows because, owing to demand elasticity, an increase in aggregate supply increases gross profit in the energy sector. An expansion in licensing increases both the gross profit in the energy market and the share of gross profit earned by licensees. Hence, since the proprietor earns a fixed share $\left(c_{0}-c\right) / c_{0}$ of gross profit of licensees, the proprietor benefits from an expansion.

\section{Incentives When the Regulatory Policy Is Fixed}

With regulation in place, to what extent will the private market step up to develop cleaner technologies? Ultimately, the incentives depend on the benefits to producers of licensing a cost-reducing innovation. In the case of tax regulation, the license allows the producer to pay less in emissions taxes. In the case of a carbon cap, the license allows the producer to buy fewer emissions allowances. Thus, the willingness to pay for licenses depends either on the tax rate or on the allowance price.

In order to compare the incentives for innovation under the two regulatory policies, the policies must be benchmarked in some way. In this section, I compare the two regulatory policies that are equivalent before the innovation, in the sense that they support the same energy supply and the same carbon emissions, such as the efficient ones. In Section V, I compare the two regulatory policies that are equivalent after the innovation, in the sense that they support the same energy supply and carbon emissions afterward if that is possible. Policies that are equivalent before the innovation will not be equivalent afterward.

Incentives in both regulatory environments depend on whether the regulated energy price is in the elastic or inelastic part of the demand curve. I first consider the elastic part of the demand curve, where the regulated price of energy is initially higher than the monopoly price. 


\section{A. Taxes and Caps When Demand Is Elastic at the Regulated Price}

First consider tax regulation, where $\tau$ is the tax on emissions and $c_{0} \tau$ is the initial regulated price of energy, higher than the monopoly price. When the proprietor introduces the clean technology, he will charge a royalty $\gamma$ on kilowatt-hours that satisfies $\gamma \leq\left(c_{0}-c\right) \tau$.

If the proprietor charges the maximum royalty, he receives a share $\left(c_{0}-c\right) / c_{0}$ of gross profit in the energy market; otherwise his share is lower. If the improvement is modest, he will charge the maximum, and energy production will not expand. For a large improvement, he may charge a royalty $\gamma<\left(c_{0}-c\right) \tau$ in order to add licensees. With a larger improvement, each licensee pays a larger royalty, so adding licensees becomes more lucrative, even if each licensee pays a slightly smaller royalty. However, the royalty will never be reduced so much that the price of energy drops below the monopoly price. In the extreme case in which $c=0$, the royalty will be the monopoly price and for positive emissions rates will be higher.

Now consider the equivalent carbon cap, $\mathbb{C}=c_{0} \mathrm{E}\left(c_{0} \tau\right)$. Because the proprietor earns a fixed fraction $\left(c_{0}-c\right) / c_{0}$ of the licensees' gross profit, we can conclude that the proprietor will always want to expand production if production is smaller than the monopoly supply. Expansion has two effects: it increases gross profit in the energy sector, and it increases the fraction of gross profit collected by licensees. If supply expands past the output that would support the monopoly price, gross profit in the energy market starts to decrease, but the second effect still makes it profitable to keep increasing total supply, although perhaps not to the maximum that is feasible under the cap.

Which policy is more lucrative for the proprietor? If full diffusion under the carbon cap leads to an energy supply that is smaller than a monopolist would offer and if the supply under tax regulation is yet smaller, then the cap-and-trade policy is more lucrative. The clean technology is fully diffused under the carbon cap, and there is more gross profit in the energy market under the carbon cap than under the tax. Further, the share of gross profit earned by the proprietor under tax regulation is no greater than the share $\left(c_{0}-c\right) / c_{0}$ earned under the carbon cap.

I make the following conclusions:

- If demand is elastic at the initial regulated price, tax regulation leads to an energy price that is higher than the monopoly price, regardless of the size of the innovation. 
- If demand is elastic at the initial regulated price, carbon regulation leads to an energy price that is lower than the monopoly price if that is feasible under the carbon cap.

- If demand is elastic at the initial and final regulated prices and if supply is greater under the carbon cap than under the tax, then the carbon cap generates more licensing revenue for the proprietor than the tax.

In figure 3, the dark lines bracket the prices that the proprietor can support with his royalty under tax regulation. The top shaded rectangle shows the proprietor's profit, which is close to the monopoly profit in the energy market if $c$ is small. The horizontally shaded area shows the proprietor's profit under cap-and-trade regulation and shows that the price will be smaller than the monopoly price if that is possible under the carbon cap.

Figure 3 illustrates a theme that will recur throughout this analysis: Under tax regulation, the royalty controls the price of energy and total energy supply, but the clean technology is fully diffused in the sense that no producers of energy use the old technology. Although there may be lags due to legacy capital, the proprietor has an incentive to license all the producers. Under a carbon cap, the royalty controls not only the prices of energy and allowances but also the fraction of the market that is served by the proprietor's licensees.

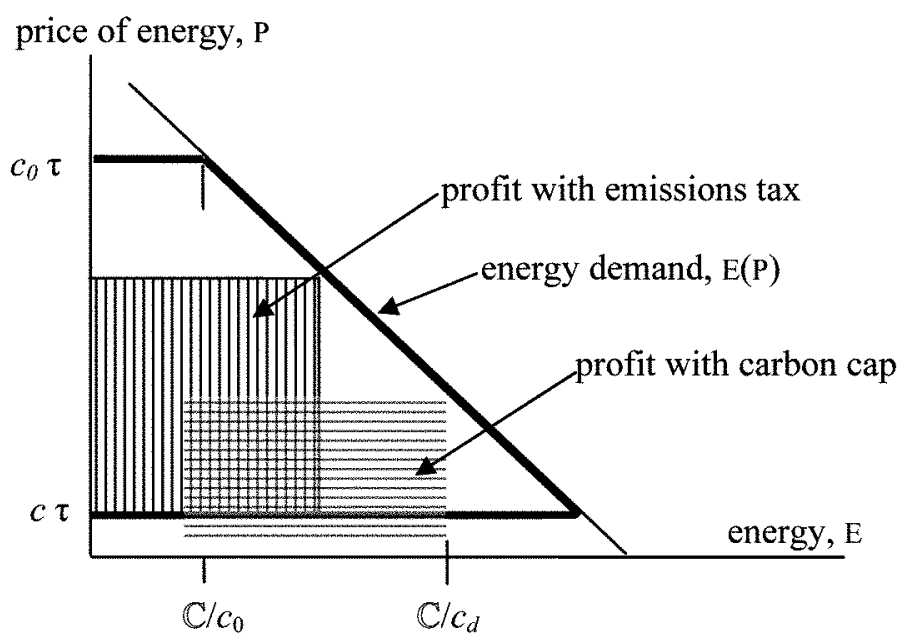

Fig. 3. Licensing revenue under tax regulation and a carbon cap, when demand is elastic at the initial regulated price. 


\section{B. Taxes and Caps When Demand Is Inelastic at the Regulated Price}

Now suppose that the regulated price is initially lower than the monopoly price. Under both regulatory policies, profit is the size of the improvement $\left(c_{0}-c\right) / c_{0}$ times the gross profit earned by the licensees. Under tax regulation, the reason is that the proprietor will choose the maximum royalty, $\gamma=\tau\left(c_{0}-c\right)$. This royalty leads to a price in the energy market that is as close as possible to the monopoly price without violating the constraint that producers are willing to license the clean technology rather than use the old technology. This is shown in figure 4 .

Under the carbon cap, the proprietor also earns the share $\left(c_{0}-c\right) / \mathcal{c}_{0}$ of licensees' profit. Whether the innovation is fully diffused or not, gross profit in the energy market, and therefore the licensees' gross profit, is smaller than under tax regulation. Hence, the proprietor earns less under a carbon cap than under tax regulation.

Assuming full diffusion, figure 5 shows two representations of profit under the carbon cap, which are equal. ${ }^{2}$ The horizontal area is the same fraction of profit as in figure 4, but at a lower price of energy and lower gross profit in the energy market. The vertically shaded area shows that the proprietor collects the commercial value of the expansion in energy supply that his licensing facilitates.

Figures 4 and 5 show how the licensing revenue matches up to the social value of the innovation. Suppose, in particular, that the regulatory policy is the efficient one, where the emissions tax is equal to the social cost of carbon emissions, $\tau=h$. With the efficient tax in place, figure 4 shows that the proprietor's per-period licensing revenue is

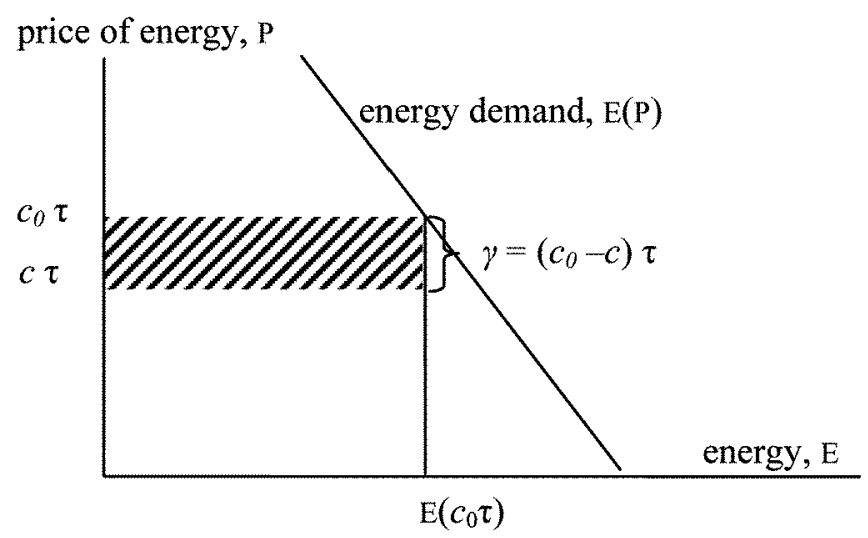

Fig. 4. Licensing revenue with a fixed emissions tax 


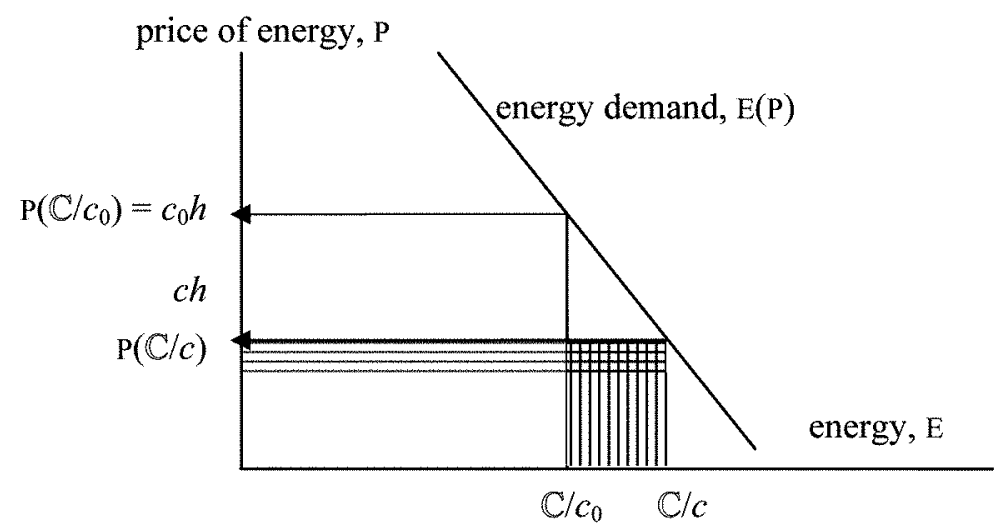

Fig. 5. Licensing revenue with a fixed carbon cap and full diffusion of the clean technology

equal to the social value of the reduced carbon emissions, namely, $\left(c_{0}-c\right) h$ times energy production. This suggests that the regulatory tax is a good incentive scheme since the innovator receives a reward that is commensurate with the social value he provides. At the same time, however, the adjustment in the market is not efficient. The entire benefit of the cleaner technology is taken as a reduction in emissions, with no expansion in energy supply. As argued above, this is not the efficient way to use the new technology.

The equivalent (efficient) carbon cap is $\mathbb{C}=c_{0} \mathrm{E}\left(c_{0} \tau\right)$. With this cap in place, the price of carbon allowances before the innovation is $c_{0} \tau$, just as with the tax $\tau=h$. This is shown in figure 5. However, the carbon emissions and energy supply are inefficiently high at the new emissions rate, as argued in Section II.

Figure 5 shows that the proprietor's per-period licensing revenue is smaller than the social value he provides under the carbon cap. The social value is not the benefit of reduced carbon, as with the emissions tax, because the carbon emissions stay fixed. The social value is the consumers' surplus from expanded energy consumption. The proprietor's licensing revenue is less than the increase in consumers' surplus.

I summarize these conclusions as follows. They imply that tax regulation is more lucrative for the proprietor than carbon regulation.

- Suppose that the emissions tax and carbon cap support equal energy production using the old technology (e.g., the efficient level). If the regulated price of energy is initially in the inelastic part of the demand curve, (1) after the innovation, cap-and-trade leads to larger energy production than an emissions tax, and to less licensing revenue for the 
proprietor; and (2) the social benefits of the improvement are taken as increased energy production under the carbon cap, but as a reduction in carbon emissions under the emissions tax.

\section{Efficiency Adjustments}

Whether emissions are regulated by a tax or a cap, the policy will generally not be efficient ex post, even if it was efficient ex ante, and there will be pressure to change the policy. It is the anticipated policy that matters for incentives, not the initial policy.

A difficulty that follows from the arguments in Section III is that there might not be a carbon cap that implements the efficient energy supply and carbon emissions. Suppose that the initial emissions rate $\mathcal{c}_{0}$ is high, and an innovator achieves a very low emissions rate $\mathcal{c}$. Let $\mathbb{C}$ be the carbon cap such that $\mathbb{C} / \mathcal{C}$ is the efficient energy supply with the cleaner technology. As discussed in Section III, energy production might not expand to $\mathbb{C} / c$. If the new emissions rate $c$ is low, the proprietor can make more profit by setting a high royalty that excludes some producers. If so, there is no ex post carbon cap that achieves static efficiency. Partial diffusion is never efficient.

However, I showed in Section III that an innovator cannot profit from a larger improvement than he would fully diffuse. The problem of partial diffusion will not arise except by accident because the innovator will avoid the diffusion problem by being less ambitious in the size of the improvement.

The problem of incomplete diffusion does not arise with a tax. There is always an emissions tax that implements the efficient energy supply and carbon emissions However, when the clean technology is proprietary, this tax is no longer equal to the social cost of emissions, $\tau=h$. In fact, it must be lower. Otherwise, the price of energy would be inefficiently high when the proprietor's royalty is added to the tax. When the optimal royalty is set as $\gamma=\tau\left(c_{0}-c\right)$, the emissions tax should be chosen as $\tau=\left(c / c_{0}\right) h<h$ instead of $\tau=h$ (Denicolo 1999). If the innovation is such that the proprietor would set $\gamma<\tau\left(c_{0}-c\right)$, then the tax rate that implements the intended energy price must be higher than $\left(c / \mathcal{c}_{0}\right) h$ but not as high as $h$.

When the royalty is $\gamma=\tau\left(c_{0}-c\right)$, the proprietor earns the fraction $\left(c_{0}-c\right) / c_{0}$ of gross profit in the energy sector. The proprietor also earns the fraction $\left(c_{0}-c\right) / c_{0}$ under the optimal carbon cap, although this is a share of licensees' profit, which can be less than the gross profit in the energy sector. 
The conclusions are as follows:

- When the clean technology is proprietary, an emissions tax that leads to static efficiency is smaller than the marginal social cost of emissions.

- For an arbitrary proprietary improvement, there might not be a carbon policy that leads to static efficiency because of the diffusion problem. There is always an emissions tax that does so.

- An adjustment from an ex ante efficient policy to an ex post efficient policy (when possible) will increase the innovator's licensing revenue under cap-and-trade regulation but will reduce it under tax regulation, provided that the demand for energy is inelastic at the initial regulated price.

- If the two policies are equivalent ex post in energy production and emissions (in particular, if both policies are efficient), then the proprietor receives at least as much licensing revenue under the carbon cap as under tax regulation. If the regulated demand is at an inelastic part of the demand curve, these are equivalent.

The third point follows because licensing revenue is a fraction $\left(c_{0}-c\right) / c_{0}$ of gross profits in the energy market, in both regimes. The optimal adjustment to the carbon cap is to tighten it up, which increases the price of energy and increases gross profits in the energy market. In the inelastic part of the demand curve, the optimal adjustment of the emissions tax is to reduce it, which reduces the price of energy and reduces gross profits in the energy market. The fourth point follows because efficiency implies full diffusion, so that the proprietor earns the fraction $\left(c_{0}-c\right) / c_{0}$ of gross profits under the carbon cap but might earn less under a tax regulation if demand is elastic.

\section{Comparing Incentives}

It is instructive to work out an example showing how the profits compare. In this example, all the action takes place in the inelastic part of the demand curve where the regulated price of energy is lower than the monopoly price.

Suppose that the marginal social cost of emissions is $h=1$ and that demand for energy is given by $\mathrm{P}(e)=2-e$. Then for each emissions rate $c$, the optimal energy price is $c$, the optimal energy production is $2-c$, and the optimal carbon output is $c(2-c)$. Let the initial emissions rate be $c_{0}=1$, which means that the initial regulated price of energy is the monopoly price in the energy market. Improvements will lead to prices in the inelastic part of the demand curve. 
Suppose that a proprietor achieves a new technology with emissions rate $c<c_{0}$. First consider the emissions tax. When energy producers must pay the efficient tax $\tau=1$ on emissions, the proprietor's most profitable royalty satisfies $\gamma=1-c$. Then the price of energy is the same as before the innovation, namely one. In addition, gross profit in the energy market is one, and the proprietor's licensing revenue is $\left(c_{0}-c\right) / c_{0}$ times one. The proprietor's revenue in the tax regime is graphed as the top dashed line in figure 6 as a function of $c / c_{0}$. Large improvements (small c) are on the left side of figure 6 .

Now consider a carbon cap. To be optimal, the carbon cap must initially be $\mathbb{C}=1$. The proprietor's revenue is the fraction $\left(c_{0}-c\right) / c_{0}$ of licensees' profit. This is shown by the solid bottom line in figure 6 as a function of the new emissions rate. The left side represents large improvements (small $c$ ), for which the proprietor will restrict the supply of licenses as discussed in Section III. This is why profit is constant for small $c$. For lesser improvements (toward the right side of the diagram), the proprietor diffuses fully, and the royalty satisfies

$$
\gamma=\left(\frac{c_{0}-c}{c_{0}}\right) \mathrm{P}\left(\frac{\mathbb{C}}{c}\right) .
$$

For each $c$, energy supply expands from $\mathbb{C} / \mathcal{c}_{0}$ to $\mathbb{C} / c$.

On the right side of the diagram, where the proprietor diffuses fully in both regulatory regimes, profit is greater in the tax regime because

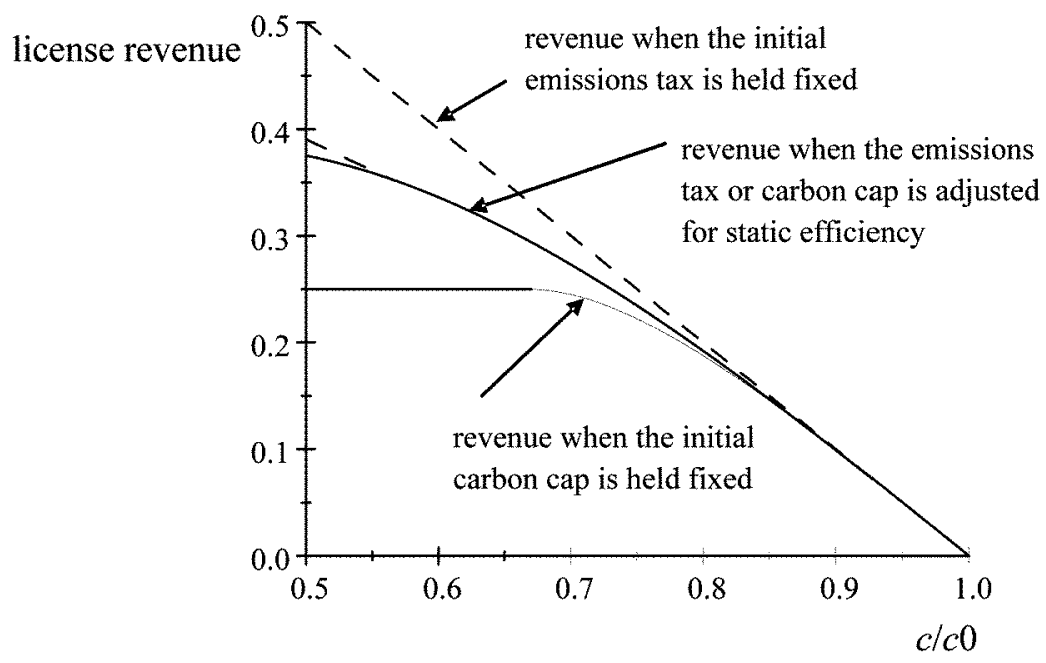

Fig. 6. Comparison of licensing revenues with a fixed emissions tax and a carbon cap 
the supply of energy is smaller, and gross profit in the energy market is larger. Hence, the proprietor's share $\left(c_{0}-c\right) / c_{0}$ is larger.

The middle line in figure 6 graphs the proprietor's licensing revenue if the policy (either the tax or the carbon cap) is adjusted for static efficiency using the new technology. This is where the tax rate falls to $c / c_{0}$ and the carbon cap is decreased to $c(2-c)$. The two regimes produce the same gross profit in the energy market, and with full diffusion, this is why the proprietor's licensing revenues are the same. At the extreme left of the diagram, there is a "spur" lying above the solid line, which reflects the fact that for low values of $c$ (large improvements), the proprietor will not provide full diffusion in the cap-and-trade regime, and his profit is larger when he excludes some producers.

Figure 6 shows that the licensing revenue can be much lower with the carbon cap than with an emissions tax when the carbon reduction is large (the left side of the graph). For smaller improvements (toward the right), the discrepancy vanishes. It also shows that, in the tax regime, the proprietor's revenue falls if the emissions tax is adjusted for static efficiency, but in the cap-and-trade regime, the proprietor's revenue rises with the analogous adjustment.

\section{The Conflict between Static Efficiency and Innovation}

It is well understood that creating rewards through intellectual property rights leads to static inefficiency. The innovator's reward derives from the power to price above private marginal cost. Static efficiency would require that the price equals the private marginal cost of production.

In the context here, however, marginal-cost pricing is not efficient. The efficient price should take into account the marginal social cost $h$ as well as the private marginal cost (assumed above to be zero). As a consequence, if energy is efficiently supplied, revenue in the energy market is larger than the private costs of producing it. Under tax regulation, the excess goes to the government. Under cap-and-trade regulation, the excess goes to the owners of allowances. When a royalty is paid, some of the excess goes to the proprietor charging royalties. Because it is efficient to restrict output, which creates profit in the energy sector, the conflict between efficient pricing and incentives to innovate is less severe than in the usual case.

However, the conflict still exists and is fully restored if an innovator achieves a carbon-free technology. With zero emissions, the efficient price of energy is the private marginal cost, which implies that gross profit in the energy sector is zero. There is no reservoir of profit out of which to reward the innovator. The regulator then faces a choice between trying to 
implement static efficiency ex post and choosing a regulatory policy that rewards the innovator. Laffont and Tirole (1996) and Montero (2010) use the term "expropriation of benefits" to describe the regulator's temptation to implement the efficient energy price ex post, thus eroding the innovator's reward.

Cap-and-trade regulation makes expropriation difficult, whereas tax regulation makes it easy (Laffont and Tirole 1996). With tax regulation, the regulator can ensure a zero price of energy by setting a tax equal to zero. Recall that the optimal tax is $\tau=\left(c / \mathcal{c}_{0}\right) h$, which is zero when $c=0$. However, with cap-and-trade regulation, a zero price cannot be achieved. If the carbon cap is set at zero, which is the efficient level of emissions, energy cannot be produced with the old, carbon-emitting technology, and the proprietor of the clean technology can earn monopoly profits in the energy market. This achieves productive efficiency, but not the efficient price. The regulator can expand output by setting a positive carbon cap, but that defeats productive efficiency. Under the reasonable assumption that all allowances will find their way into use, all the allowances will be used in producing energy with the dirty technology. A high cap will get close to the efficient price, but only with high carbon emissions and a low reward to the innovator (Montero 2010).

Thus, a carbon cap does a better job than tax regulation of protecting the innovator from the overzealous regulator who wants to achieve static efficiency ex post. At the same time, cap-and-trade regulation creates a tension between consumption efficiency (a low price) and productive efficiency (full diffusion).

In any case, realizing that the threat of expropriation will deter innovation, the regulator may want to commit against it. Suppose now that the regulator is concerned explicitly with innovation and can commit to a policy that will not be efficient ex post. The commitment aspect is key. Potential innovators must be convinced that the regulator cannot renege on this commitment and will not expropriate the value of the innovation on behalf of energy users.

To compare taxes and carbon caps we must now benchmark the policies differently than above, where they were benchmarked to efficiency. Denicolo (1999) benchmarks the policies to a given level of carbon emissions rather than to policies that are efficient and asks which policy leads to more innovation. Instead of taking the size of improvement as given and asking which policy provides larger rewards, as above, he takes as given that the policy will achieve a given level of carbon emissions. There are two ways to achieve the target: with a high energy supply and a large improvement in the emissions rate or with a 
low energy supply and a smaller improvement in the emissions rate. If tax regulation and a carbon cap would both achieve the same total emissions, which achieves the larger energy supply and larger improvement?

The thrust of the arguments above is that tax regulation is more lucrative for the innovator whenever demand is inelastic at the regulated price of energy, and carbon regulation may be more lucrative otherwise. This suggests that tax regulation will be less (more) conducive to innovation according to whether demand is elastic (inelastic) at the regulated price and that tax regulation can achieve the given level of emissions at a lower (higher) energy supply than a cap.

To see this, suppose that an emissions tax $\tau$ leads to an improvement $\left(c_{0}-c\right) / \mathcal{c}_{0}$ and to an emissions level $\mathcal{C E}(\tau \mathcal{c})=\mathbb{C}$. Following Denicolo (1999), it is particularly easy to compare the tax with the carbon cap for parameters such that the proprietor would choose the maximum royalty under tax regulation and such that he would diffuse the innovation fully under the carbon cap. After reprising this argument, I explain why the same result holds when the tax-regulated proprietor might choose a royalty that is lower than the maximum or might not diffuse fully under a carbon cap.

If the proprietor would choose the maximum royalty $\gamma=\tau\left(c_{0}-c\right)$ under tax regulation and would diffuse the innovation fully under the carbon cap, the proprietor earns the fraction $\left(c_{0}-c\right) / \mathcal{c}_{0}$ of gross profit in both regulatory regimes. With tax regulation, the proprietor's licensing revenue is $\left[\left(c_{0}-c\right) / \mathcal{c}_{0}\right] G(e)$, where $e$ is the energy supply and $G(e)$ is gross profit in the energy market. The marginal profit available from a marginal reduction in $c$ is

$$
-\frac{d}{d c}\left(\frac{c_{0}-c}{c_{0}}\right) G(e)
$$

Now suppose that the carbon cap is $\mathbb{C}$ so that $e=\mathbb{C} / c$, and the innovator makes the same improvement, to $c$. With cap-and-trade regulation, the proprietor's licensing revenue as a function of $c$ is $\left[\left(c_{0}-c\right) / c_{0}\right] G(\mathbb{C} / c)$. The marginal profit available from that last marginal reduction in $c$ is

$$
-\frac{d}{d c}\left(\frac{c_{0}-c}{c_{0}}\right) G\left(\frac{\mathbb{C}}{c}\right)
$$

Then

$$
-\frac{d}{d c}\left(\frac{c_{0}-c}{c_{0}}\right) G(e)>-\frac{d}{d c}\left(\frac{c_{0}-c}{c_{0}}\right) G\left(\frac{\mathbb{C}}{c}\right)
$$


if $\mathbb{C} / c=e$ and demand is inelastic at $e$ and

$$
-\frac{d}{d c}\left(\frac{c_{0}-c}{c_{0}}\right) G(e)<-\frac{d}{d c}\left(\frac{c_{0}-c}{c_{0}}\right) G\left(\frac{\mathbb{C}}{c}\right)
$$

if $\mathbb{C} / \mathcal{C}=e$ and demand is elastic at $e$.

Because an incremental reduction in the emissions rate increases energy supply and gross profit $\mathrm{G}(\cdot)$ under a carbon cap but not under tax regulation, the marginal reduction in $c$ is more (less) lucrative under tax regulation than under carbon regulation if energy supply is in the inelastic (elastic) part of the demand curve. In the inelastic part of the demand curve, the marginal benefit from reducing $c$ is larger under tax regulation than under carbon regulation, and this will lead to a larger improvement.

The inequalities above show that the relative incentives to invest are driven by the change in gross profit in the energy sector. In both regulatory regimes, the innovator earns the same fraction of gross profit in the energy sector, namely, the size of the improvement. In both regimes, making a larger improvement increases the innovator's share of gross profit. However, in the case of a carbon cap, there is a second effect: the gross profit changes as $c$ changes. The reason is that the supply of energy increases and its price falls. The gross profit increases if the energy supply is in the elastic part of the demand curve and decreases if the energy supply is in the inelastic part of the demand curve.

Now suppose that, under tax regulation, the proprietor's best royalty is less than its maximum, $\gamma<\tau\left(c_{0}-c\right)$, so that, as with cap-and-trade, the innovator's licensing strategy expands the energy supply. The taxregulated proprietor will do this only in the elastic part of the demand curve, where the expansion in energy supply increases gross profit in the energy sector. The innovator's share of profit remains fixed at $\left(c_{0}-c\right) / c_{0}$ under cap-and-trade regulation, whereas the expansion reduces the proprietor's share of profit under tax regulation. Therefore, reducing $c$ at the margin is less profitable under tax regulation than under cap-and-trade regulation. ${ }^{3}$

Finally, it is only in the inelastic part of the demand curve where the improvement might not be fully diffused under a carbon cap. This further weakens the incentives under a carbon cap. As shown in Section III, the innovator will not invest in a larger improvement than would be fully diffused because it does not add to licensing revenue.

How this matters for the innovative process depends on the nature of innovation. Denicolo (1999) and Montero (2010) give a classical analysis 
in which there is a production function for reducing the emissions rate, and the marginal cost of reducing $c$ is increasing. The innovator's best response to the regulatory policy is to achieve the size of improvement such that the marginal licensing revenue is equal to the marginal cost of improving the emissions rate. On that reasoning, I can make the following conclusions:

- Consider an emissions tax and a carbon cap that both lead to the same carbon emissions after innovation, and suppose that the resulting energy supplies are in the inelastic part of the demand curve. Then the carbon emissions are achieved with a higher energy supply and larger innovation under tax regulation than under cap-and-trade regulation.

- Consider an emissions tax and a carbon cap that both lead to the same carbon emissions after innovation, and suppose that the resulting energy supplies are in the elastic part of the demand curve. Then the carbon emissions are achieved with a lower energy supply and a smaller improvement under tax regulation than under cap-and-trade regulation.

\section{Conclusion}

Any regulatory policy that imposes financial burdens for emitting carbon also creates an incentive to invest in carbon-reducing technologies. Emissions taxes and carbon caps are two such policies. While these two policies can be made equivalent from the static standpoint of managing the trade-off between energy production and carbon emissions, they are not necessarily equivalent from the point of view of encouraging innovation.

The main arguments in this paper can be summarized as follows:

- When the demand for energy is inelastic, cap-and-trade regulation may lead to incomplete diffusion of a new technology, whereas tax regulation gives an incentive to diffuse the innovation fully.

- Tax regulation creates higher (lower) rewards for innovation than cap-and-trade regulation when energy production is in the inelastic (elastic) part of the demand curve.

- When the clean technology has a very low emissions rate, the conflict between static efficiency and incentives to innovate is particularly acute.

The first point can be understood in traditional language about markets. Under cap-and-trade regulation, there are three markets: the market 
for energy, the market for allowances, and the market for licenses. Under cap-and-trade regulation, allowances and licenses are substitutes for an energy producer. Therefore, an increase in the royalty rate leads to an increase in the allowance price. The "allowance price" under tax regulation is the emissions tax, and it cannot adjust. Therefore, the demand for licenses is more elastic under cap-and-trade than under tax regulation, and the proprietor must charge a lower royalty in order to reach full diffusion. As a consequence, full diffusion might not be the most profitable strategy.

The second point follows from how gross profit in the energy market changes when supply expands. It is not misleading to think about the case in which the proprietor would diffuse the innovation fully under cap-and-trade and would charge the maximum royalty under tax regulation. Under both policies, the proprietor collects a fixed fraction of profit in the energy market, namely, equal to the size of the improvement. Licensing expands energy production under a carbon cap but not under an emissions tax. In the elastic (inelastic) part of the demand curve, the expansion increases (decreases) profit in the energy market, and the proprietor's profit changes proportionately.

The third point echoes a familiar conflict between static efficiency and rewards to innovation. Here, static efficiency means achieving the right balance of energy production and carbon emissions, conditional on the emissions rate. If the new technology is very clean, a low price of energy is efficient ex post, leading to low gross profits in the energy market and a small reward to the innovator. The low price can easily be achieved with tax regulation but cannot be achieved under a carbon cap without tolerating more emissions than are necessary.

The conflict between static efficiency and innovation surfaces immediately if one thinks about clean technologies such as solar energy or wind power. The emissions rate for each of these technologies is essentially zero. In countries where clean energy is not subsidized on the demand side, solar power remains insignificant because of high capital costs (Borenstein 2008). Wind power seems more cost-competitive for suitable sites, but there are not enough sites (DeCarolis and Keith 2006). In any case, what creates the incentive to invest in these technologies? Under cap-and-trade regulation, a low carbon cap (such as zero) could limit the amount of energy produced with the polluting technology and could confer substantial market power on the innovator. This creates an incentive to innovate, but the benefits of the clean technology are then taken as lower emissions, without facilitating a lower price of energy, as would be efficient.

Another form of regulation is to set production standards directly. Although he does not focus on innovation, Holland (2009) points out that 
standards can be better than either taxes or carbon caps because standards have different price effects. Climate change is a global externality, and the solution must be global. Nevertheless, countries are not equally willing to control emissions. Regulation imposes costs on local industry. As a consequence, local production might be replaced by imports from nonregulating trading partners. This defeats the purpose of regulation and also creates a political obstacle. Although standards cut into profit, they might impose capital costs without imposing marginal costs and will then have less effect on the price of energy. Producers with market power might be able to absorb the cost and stay in business, even if trading partners do not regulate.

The most direct solution is government subsidies for clean technologies. The obstacle here is international free-riding (Scotchmer 2004b). Without an international treaty for joint development, the costs of the clean technology are paid by taxpayers in a single country. If the technologies are put in the public domain, other countries can use them without paying royalties, which creates a positive externality for the subsidizer due to the global nature of externalities but also relieves the other countries of sharing the cost of innovation. The free-riding problem may be one reason that more and more government-sponsored innovation is made available only under a royalty arrangement (Scotchmer 2004a, chap. 8).

The choice between emissions taxes and carbon caps has aspects not addressed in this paper. These are nicely laid out by Parry and Pizer (2007), pointing out, for example, how the policies compare in terms of the uncertainty they create for producers, their political viability, and the revenue consequences for the government.

Economists have a long history of studying price versus quantity regulation, although not with a focus on innovation. The focus has been on which instrument deals best with asymmetric information rather than which instrument gives best incentives for innovation (see Kaplow and Shavell [2002] for a synopsis and critique). As far as I know, it is only in the context of energy that the comparison has focused on innovation.

\section{Endnotes}

I thank the Climate and Energy Policy Institute, Law School, University of California, Berkeley, the Toulouse Network on Information Technology, and National Science Foundation grants SES 0531184 and 0830186 for support. I thank Ian Parry, Caroline Fischer, Vincenzo Denicolo, Juan-Pablo Montero, Molly Van Houweling, Rebecca Eisenberg, Joshua Lerner, Scott Stern, Steve Maurer, and Talha Syed for useful comments and Ity Shurtz for able assistance. 
1. To see why, suppose that the supply produced under license, say $\hat{e}$, leads to total energy supply $\mathbb{C} / c_{d}$. Then $\hat{e}$ must satisfy

$$
\hat{e}\left(\frac{c_{0}-c}{c_{0}}\right)=\frac{\mathbb{C}}{c_{d}}-\frac{\mathbb{C}}{c_{0}} .
$$

For an improvement $c$ and licensing $\hat{e}$, the innovator's licensing revenue is given by the left side of the following equality:

$$
\left(\frac{c_{0}-c}{c_{0}}\right) \hat{e} \mathrm{P}\left(\frac{\mathbb{C}}{c_{d}}\right)=\left(\frac{\mathbb{C}}{c_{d}}-\frac{\mathbb{C}}{c_{0}}\right) \mathrm{P}\left(\frac{\mathbb{C}}{c_{d}}\right)=\frac{\mathbb{C}}{c_{d}}\left(\frac{c_{0}-c_{d}}{c_{0}}\right) \mathrm{P}\left(\frac{\mathbb{C}}{c_{d}}\right) .
$$

The exact improvement $c$ (which satisfies $c<c_{d}$ ) disappears in the rearrangement on the right side of the equality.

2. With full diffusion (and using the expression in n. 1 with $\mathbb{C} / c_{d}=\mathbb{C} / c$ ), the proprietor's profit under a carbon cap is

$$
\left(\frac{\mathbb{C}}{c_{0}}-\frac{\mathbb{C}}{c}\right) P\left(\frac{\mathbb{C}}{c}\right)=\left(\frac{c_{0}-c}{c_{0}}\right)\left[\frac{\mathbb{C}}{c} \mathrm{P}\left(\frac{\mathbb{C}}{c}\right)\right]
$$

3. Under tax regulation, the proprietor's profit is $\pi^{\tau}=\gamma \mathrm{E}(\gamma+c \tau)$. When the royalty $\gamma$ is chosen optimally, it holds that

$$
\gamma=\frac{-E(\gamma+c \tau)}{E^{\prime}(\gamma+c \tau)}=-E(\gamma+c \tau) P^{\prime}[E(\gamma+c \tau)]
$$

Then the derivative of profit with respect to $c$ is

$$
\frac{d}{d c} \pi^{\tau}=\tau \gamma \mathrm{E}^{\prime}(\gamma+\mathcal{c} \tau)=-\tau \mathrm{E}(\gamma+\mathcal{c} \tau)
$$

The proprietor's profit under the equivalent tax cap $\mathbb{C}=c \mathrm{E}(\gamma+\mathcal{c} \tau)$ is

$$
\pi^{\mathcal{c}}=\left(\frac{\mathbb{C}}{\mathcal{c}}-\frac{\mathbb{C}}{\mathcal{c}_{0}}\right) \mathrm{P}\left(\frac{\mathbb{C}}{\mathcal{c}}\right)
$$

Recognizing that an improvement entails $d c<0$, we must show that $(d / d c) \pi^{\tau}>$ $(d / d c) \pi^{c}$. Because the hypotheses that the two policies lead to the same emissions rate, the same energy output, and the same energy price, $\mathrm{P}(\mathbb{C} / c)=\gamma+c \tau$ and $\mathrm{E}(\gamma+c \tau)=\mathbb{C} / c$. Therefore,

$$
\begin{aligned}
\frac{d}{d c} \pi^{\tau} & =-\tau \mathrm{E}(\gamma+c \tau)=-\tau \frac{\mathbb{C}}{c}=\frac{\mathbb{C}}{\mathcal{c}^{2}}\left[-\mathrm{P}\left(\frac{\mathbb{C}}{\mathcal{c}}\right)-\frac{\mathbb{C}}{c} \mathrm{P}^{\prime}\left(\frac{\mathbb{C}}{\mathcal{c}}\right)\right] \\
> & \frac{\mathbb{C}}{c^{2}}\left[-\mathrm{P}\left(\frac{\mathbb{C}}{\mathcal{c}}\right)-\frac{\mathbb{C}}{c}\left(\frac{c_{0}-\mathcal{c}}{c_{0}}\right) \mathrm{P}^{\prime}\left(\frac{\mathbb{C}}{c}\right)\right]=\frac{d}{d c} \pi^{c}
\end{aligned}
$$




\section{References}

Borenstein, Severin. 2008. "The Market Value and Cost of Solar Photovoltaic Electricity Production." Working paper no. 176, University of California, Berkeley, Energy Institute, Center for the Study of Energy Markets.

DeCarolis, Joseph F., and David W. Keith. 2006. "The Economics of Large-Scale Wind Power in a Carbon Constrained World." Energy Policy 34:395-410.

Denicolo, Vincenzo. 1999. "Pollution-Reducing Innovations under Taxes or Permits." Oxford Economic Papers 51:184-99.

Fischer, C., I. W. H. Parry, and W. A. Pizer. 2003. "Instrument Choice for Environmental Protection When Technological Innovation Is Endogenous." Journal of Environmental Economics and Management 45:523-45.

Holland, Stephen. 2009. "Taxes and Trading versus Intensity Standards: SecondBest Environmental Policies with Incomplete Regulation (Leakage) or Market Power." Working Paper no. 15262, NBER, Cambridge, MA.

Jung, C., K. Krutilla, and R. Boyd. 1996. "Incentives for Advanced Pollution Abatement Technology at the Industry Level: An Evaluation of Policy Alternatives." Journal of Environmental Economics and Management 30:95-111.

Kaplow, Louis, and Steven Shavell. 2002. "On the Superiority of Corrective Taxes to Quantity Regulation." American Law and Economics Review 4:1-17.

Laffont, Jean-Jacques, and Jean Tirole. 1996. "Pollution Permits and Environmental Innovation." Journal of Public Economics 42:127-40.

Milliman, S. R., and R. Prince. 1989. "Firm Incentives to Promote Technological Change in Pollution Control." Journal of Environmental Economics and Management 17:247-65.

Montero, Juan-Pablo. 2010. "Prices vs. Quantities for the Development of Clean Technologies: The Role of Commitment." Conference paper (March), NBER, Cambridge, MA.

Parry, I. W. H. 1995. “Optimal Pollution Taxes and Endogenous Technological Progress." Resource and Energy Economics 17:69-85.

- 2003. "On the Implications of Technological Innovation for Environmental Policy." Environment and Development Economics 8:57-76.

Parry, I. W. H., and W. A. Pizer. 2007. "Emissions Trading versus CO2 Taxes." Discussion paper, Resources for the Future, Washington, DC.

Scotchmer, Suzanne. 2004a. Innovation and Incentives. Cambridge, MA: MIT Press.

. 2004b. "The Political Economy of Intellectual Property Treaties." Journal of Law, Economics, and Organization 20:415-37. 
